\title{
La cimentación del edificio histórico de la Fábrica de Tabacos de la Universidad de Sevilla
}

\author{
The foundation of "la Fábrica de Tabacos", an University of \\ Seville historic building \\ C. González García de Velasco ${ }^{(*)}$, M. González Vílchez ${ }^{(*)}$.
}

\section{RESUMEN}

Una de las principales obras a llevar a cabo en la rehabilitación del edificio de "La Fábrica de Tabacos" de la Universidad de Sevilla, es la ejecución de galerías subterráneas para el tendido de las instalaciones necesarias para sus nuevos usos. Para poder realizar estas galerías se necesita conocer las dimensiones y tipología de las cimentaciones del edificio, lo que nos podría desvelar la posibilidad de existencia de restos arqueológicos en el subsuelo.

El objetivo del presente trabajo persigue, tanto a través del estudio de la historia del edificio como mediante prospecciones, conocer la tipología de sus cimentaciones para determinar las posibilidades físicas de ejecutar dichas galerías, y para deducir de ello la posible existencia de restos arqueológicos que pudieran afectar a las futuras obras a desarrollar por la Universidad de Sevilla.

De todo ello se deduce que el edificio se asienta sobre un terreno antiguamente deprimido, que fue además excavado en toda la extensión de su planta, y cuyos cimientos fueron ejecutados desde la rasante inferior como fábricas aparejadas, rellenándose posteriormente el solar hasta la rasante actual mediante la aportación de tierras.

820-4

Palabras clave: Fábrica de Tabacos, cimentación de ladrillo, cimentación de piedra.

\section{SUMMARY}

One of the main works to be developed by the University of Seville in the building of "La Fábrica de Tabacos" restoration, consists of an underground galleries net to pass by installations and other facilitites for the new uses of this historic building. To execute these galleries, we need to know the dimensions and typologies of the building foundations and also the history of its construction, because it could reveal us the possible existence of archaeological remains.

This paper investigates, both through the building history and through some specific underground explorations, the knowledge of this building foundations and the real possibilities to carry out these galleries without archaeological incidences.

The building sits on a land formerly depressed and later excavated to the full extent of the plant, and whose foundations were executed from below as walls and pillars, and being later all the plant filled to the ground level by providing current soil.

Keywords: "Fábrica de Tabacos", brick foundations, stone foundations 


\section{ANTECEDENTES DEL EDIFICIO}

La primitiva Real Fábrica de Tabacos de SeviIla, construida en el siglo XVIII y convertida hoy en sede del Rectorado de la Universidad de Sevilla y de algunas de sus Facultades, es el edificio industrial de mayores dimensiones y máxima categoría arquitectónica en España. Ocupa un enorme rectángulo de $185 \times 147 \mathrm{~m}$, solamente superado en planta en nuestro país por El Escorial, y su azotea es la de mayor extensión del mundo. El edificio se situó extramuros, en las proximidades de las murallas de la ciudad, cerca de la Puerta de Jerez, y en una gran explanada sensiblemente horizontal existente entre el arroyo Tagarete y el río Guadalquivir (Figura. 1).

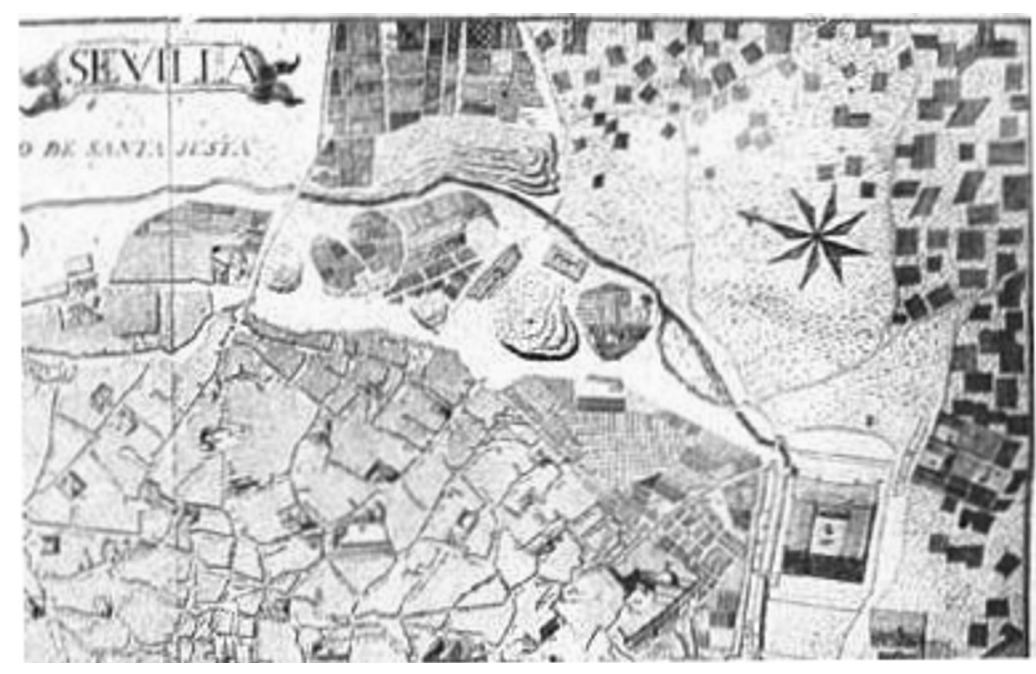

. La Fábrica de Tabacos en el primer plano de Sevilla (Plano de Olavide), de 1771 .
La mayor parte del edificio, de una altura de dos plantas, está ejecutada por yuxtaposición de bóvedas de casquete esférico y de planta cuadrada, cada una de ellas apoyada sobre cuatro pilares ejecutados en piedra arenisca de sección cruciforme, situados a una distancia entre sí de 7 varas castellanas (5,87 m). Las fachadas también fueron ejecutadas en esta piedra, procedente en su mayor parte de las canteras del Puerto de Santa María, mientras que las fábricas interiores y las bóvedas se ejecutaron en su mayoría de ladrillo. Las obras se terminaron en el último tercio del siglo XVIII, correspondiendo la mayor parte de su dirección al ingeniero militar Sebastián Van Der Borch, intendente de la real fábrica (1).

El edificio sufrió una gran reforma en la década de 1950 para su adaptación a sede de la Universidad de Sevilla, produciéndose, en su interior, importantes demoliciones que alcanzaron a una tercera parte de lo edificado (2). Hoy, la Fábrica de Tabacos, está catalogada como Bien de Interés Cultural y, recientemente, la Universidad ha redactado un Plan Director de Remodelación del edificio, que ya ha sido aprobado por la Comisión Provincial del Patrimonio Histórico Artístico de la Delegación de Cultura de la Junta de Andalucía (3).

\section{ANTECEDENTES DEL PRESENTE TRABAJO}

La Universidad de Sevilla tiene previsto Ilevar a cabo, a lo largo de los próximos años, una remodelación profunda del edificio de la primitiva Fábrica de Tabacos de Sevilla, sede del Rectorado y la Universidad de Sevilla, siendo necesaria la ejecución de galerías subterráneas para el tendido de nuevas instalaciones. Para poder realizar estas galerías se necesita conocer las dimensiones y tipología de las cimentaciones del edificio, lo que nos podría desvelar la posibilidad de existencia de restos arqueológicos en el subsuelo.

El presente trabajo tiene por objeto llevar a cabo una investigación sobre la tipología constructiva de las cimentaciones del citado edificio de la Fábrica de Tabacos de la Universidad de Sevilla así como sobre los sistemas constructivos empleados en la ejecución de las mismas. Se ha contado para su realización con personal y medios auxiliares que la Universidad de Sevilla ha puesto a disposición de los autores para efectuar las excavaciones y prospecciones necesarias.

Dada la catalogación del inmueble como BIC, la Delegación de Cultura exige unas determinadas cautelas arqueológicas sobre las estructuras bajo rasante, tanto para preservar cualesquiera elementos de interés del edificio, como los hallazgos arqueológicos que pudieran aparecer en las excavaciones. Las citadas cautelas obligan a la Universidad de Sevilla a la redacción de un proyecto arqueológico a aprobar por la Delegación Provincial de Cultura, y a una posterior intervención arqueológica de ejecución de catas, con remoción manual de tierras, para que el arqueólogo pueda presentar un informe a la citada Delegación, que podría afectar o condicionar la ejecución de las futuras obras en el terreno reconocido. Dichas obras futuras habrán de respetar las recomendaciones que la Delegación de Cultura haga, como consecuencia del informe arqueológico.

La importancia de los resultados del presente trabajo es grande, ya que de ellos se derivarán consecuencias que afectarán a los futuros proyectos de obras en el edificio. En concreto, la Universidad de Sevilla se ve obligada a ejecutar unas importantes galerías subterráneas de instalaciones en el edificio para su modernización y adecuación a las normativas vigentes en la actualidad, por lo que es de gran importancia conocer previamente las probabilidades que existen de encontrar restos arqueológicos en el 


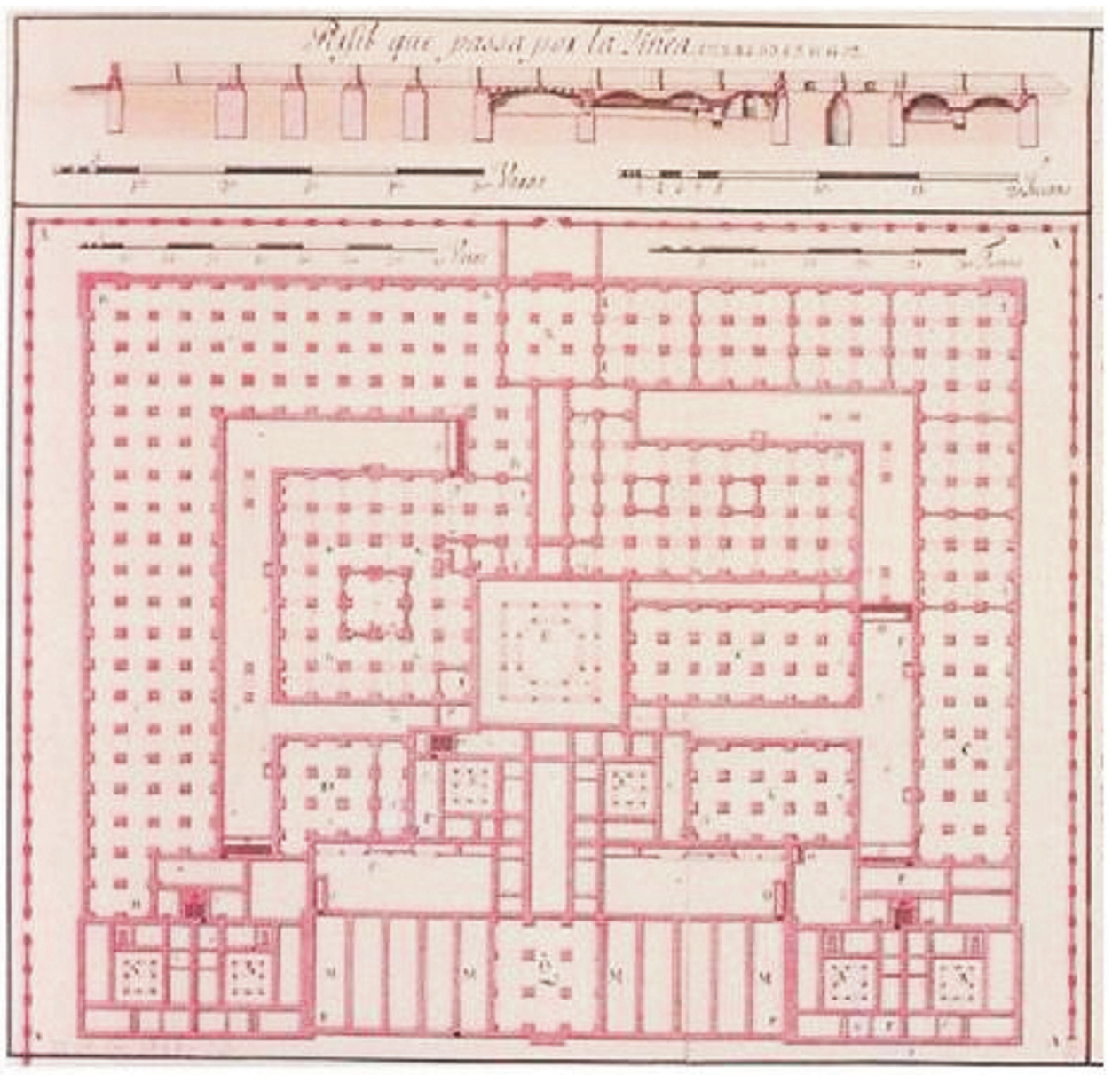

subsuelo del inmueble, dado que su aparición retrasaría gravemente la marcha de los citados trabajos.

\section{OBJETIVOS DE LA INVESTIGACIÓN}

Los objetivos del presente trabajo consisten fundamentalmente en averiguar qué materiales y sistemas constructivos se emplearon en la construcción de los cimientos del primitivo edificio de la Fábrica de Tabacos, así como establecer cuáles fueron los trabajos previos a la realización de las fundaciones ya que todo ello podría arrojar luz sobre la cimentación realmente ejecutada y aclarar las posibilidades de hallar restos arqueológicos bajo el edificio. Por otra parte, se persigue obtener un mejor conocimiento de la cimentación del edificio para ponerlo de manifiesto a los autores de los futuros proyectos de reforma del mismo.

\section{CONSIDERACIONES HISTÓRICAS}

Según se observa en el plano de cimientos del edificio, de fecha 1745 (Figura 2), los muros de fachada del mismo, así como otros muros interiores, están cimentados mediante zapatas corridas, mientras que los pilares del edificio lo están mediante zapatas aisladas de planta cuadrada y de unos 2,00 m de lado.
En la investigación de Morales Sánchez (4) sobre la arquitectura y la autoría del edificio de la primitiva Fábrica de Tabacos (investigación historicista sobre los diversos proyectos desarrollados en el siglo XVIII), no se define cómo se ejecutaron las excavaciones, ni el alcance de éstas. Tampoco se informa de los sistemas y procesos constructivos empleados en general en la construcción del edificio, ni de los materiales con los que se ejecutaron los cimientos. Sí, en cambio, se ofrecen las transcripciones de determinados legajos estudiados por el autor en el Archivo General de Simancas que, aunque se acompañan en el libro de Morales con carácter histórico, arrojan a nuestro entender, en algunas de sus aseveraciones, no poca luz sobre la ejecución de la cimentación de la primitiva Fábrica.

Citamos a continuación pues, las referencias más interesantes que hemos encontrado en dichas citas de los antiguos legajos con respecto a la ejecución de los cimientos del edificio, correspondientes todas ellas a las cartas entre intendentes de la Fábrica y personal diverso relacionado con la construcción del edificio (se respeta la grafía de los documentos):

a) "Primeramente la excavación que se considera se deverá hacer para estos fundamentos, 
según las calas que se han avierto en el terreno, llegará a 65.600 varas cúbicas..."

b) "Para los perfiles reconozerá Vs que lebanto el piso de este edificio con tierra, y quedarán las excavaciones a una altura mayor que la que tiene oy el terreno, lo que he ejecutado con bastante reflexion en lo de las abenidas del rio, por lo qual el piso del edificio, un pie mas alto que la abenida del año1684..."

c) "Soy de sentir que se haga un solo asiento de los fundamentos y mudanza del Tagarete el qual será de bastante entidad,...prebiniendo que como en los fundamentos, no obstante haberse reconocido el terreno en quatro diferentes partes, no se puede saber las diferentes calidades, ... que se llegue a su ejecución tal vez augmentar o disminuir algunas porciones de excavación..."

d) "Hera su dictamen no ser tan falible el terreno como lo expresa el maestro Azero, y que en caso de que lo fuese, quando el yngeniero Bordik bolvio a plantificar los pilares profundandolos mucho mas de lo que estaban, no los pondria en terreno inseguro..."

e) "Pues hasta ahora, según las noticias con que se halla la direccion, solo se ben picados los zimientos de la obra a igualdad del terreno que se eligió para hazerla..."

e) "Hallándose la obra con solo los cimientos ejecutados, y que me parece que son estos bastantemente robustos para sostentar el peso del edificio propuesto, que la planta de dichos cimientos permite poder dar mas grueso de lo previsto a pilares y murallas..."

De lo anteriormente expuesto se deduce que el terreno donde se levantó el edificio era sin duda un territorio deprimido e inundable, entre los cauces del Guadalquivir y el Taga-

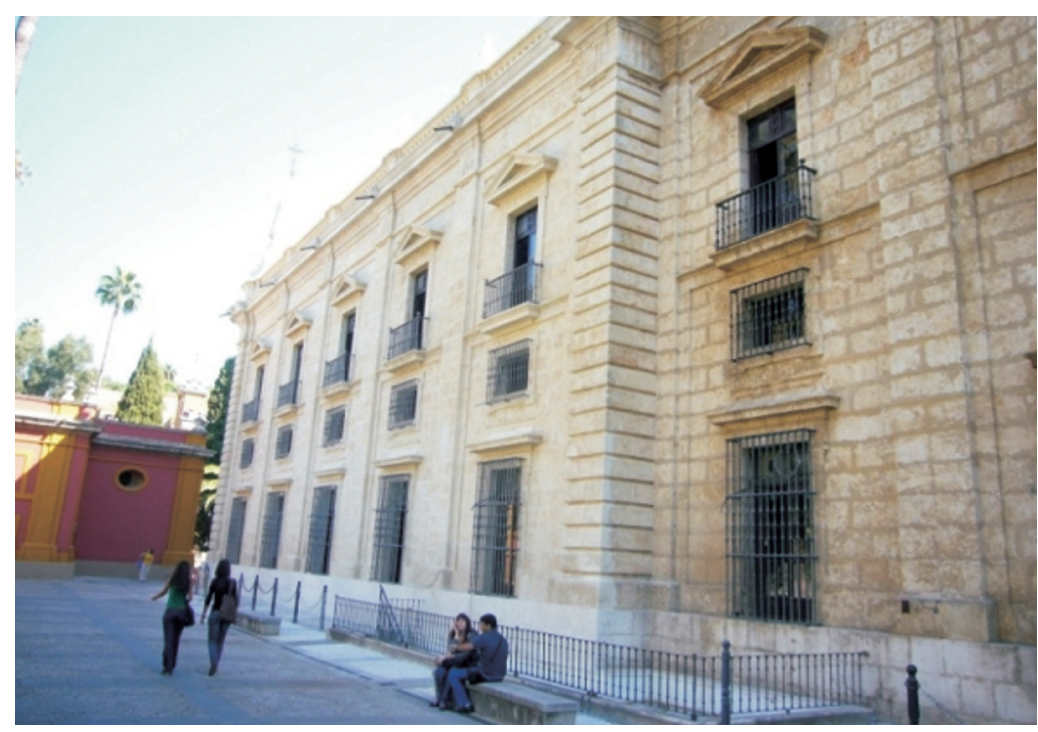

rete, de topografía sensiblemente horizontal y homogénea, y cuya rasante natural se encontraba más baja que la actual rasante de la calle San Fernando. Para ampliar más el espacio útil del edificio se excavó un nuevo cauce rectilíneo para el Tagarete, junto a las murallas de la ciudad, lo que permitiría construir el edificio y canalizar adecuadamente el arroyo para evitar inundaciones.

La decisión de que la rasante de la planta baja estuviera por encima de las avenidas del río, permitía la ejecución al aire de una buena parte de los cimientos, no obstante lo cual, se iba a llevar a cabo una importante excavación general del solar, buscando un buen terreno de apoyo de la cimentación. La media de excavación total realizada la deducimos del dato de las 65.600 varas cúbicas de excavación efectuada (unos $40.000 \mathrm{~m}^{3}$ ) lo que, aplicado a la planta del edificio y su entorno inmediato (unos $30.000 \mathrm{~m}^{2}$ ) resultaría una excavación media de 1,30 m, a partir de la cual se iniciaría el labrado de las zapatas. Esto indica claramente que el terreno se encontraba en principio bastante deprimido, en relación con la rasante a la que habría que situar la planta baja del edificio.

Parece ser que existieron discrepancias entre distintos maestros de obras sobre la capacidad resistente del terreno acordado, por lo que se acabó profundizando más la excavación hasta encontrar un mejor terreno. También queda claro que se rellenó con tierra la totalidad del solar, una vez terminados de ejecutar los cimientos, lo que supuso elevar la rasante de la parcela varios metros sobre su primitiva situación.

\section{ESTADO DE LA CUESTIÓN}

El estado de la cuestión relativa a los sistemas de cimentación del edificio de la Real Fábrica de Tabacos de Sevilla, en el momento de redacción del presente trabajo, refleja un absoluto desconocimiento en esta materia, ya que no existen trabajos de investigación, publicaciones científicas, históricas o técnicas que aporten algún dato acerca de las tipologías de cimientos del edificio, sus dimensiones, características físicas y mecánicas, ubicación en el terreno, etc.

El presente trabajo es, por tanto, el primero que aborda esta cuestión y, sin pretender agotar el tema, presenta los primeros datos reales sobre la cimentación del edificio, que sin duda serán seguidos por próximos trabajos de investigación práctica, apoyados en las obras de reforma del edificio que la Universidad de Sevilla tiene planificadas al amparo del Plan Director citado con anterioridad.

El planteamiento previo a nuestro trabajo determinaba que las tipologías de las zapatas del 
edificio de la Fábrica de Tabacos podrían haber sido de tres clases:

a) De hormigón ciclópeo de piedras y cal.

b) De fábrica de sillares concertados.

c) De fábrica de ladrillo debidamente aparejada.

El conocimiento de este dato era de suma importancia para nuestro trabajo pues, en caso de que las zapatas se hubiesen ejecutado con fábricas de ladrillo o con fábricas de sillares de piedra, bien concertadas y aparejadas, su realización se habría tenido que llevar a cabo por hiladas, de abajo a arriba, por lo que el plano inicial de trabajo habría coincidido con el plano de asiento de la cimentación, previa excavación y desmonte general del entorno. Por el contrario, si los cimientos hubiesen estado confeccionados con un hormigón de cal y piedras, sin duda habrían sido ejecutados por vertido desde la rasante natural, rellenando pozos de cimentación excavados previamente en el terreno.

La ejecución de los cimientos como fábricas aparejadas en piedra o ladrillo, habría implicado muy posiblemente un vaciado general de la planta del edificio, al menos por grandes áreas en las que pudiera haberse llevado a cabo el transporte y trasiego de materiales (acarreados por animales), así como la ubicación de elementos auxiliares de ejecución, como andamios, plataformas de trabajo, poleas, etc. Ello habría implicado la total desaparición de posibles restos arqueológicos hasta dicha cota de excavación, al menos en el espacio bajo el edificio, lo que permitiría ahora a la Universidad ejecutar bajo la rasante del mismo las ya mencionadas galerías de instalaciones con una seguridad casi absoluta de no encontrar restos arqueológicos.

El sistema alternativo, esto es, la excavación de los pozos de cimentación, uno a uno a cielo abierto, habría constituido un sistema de construcción dificultoso y no exento de peligro, ya que por los estrechos espacios de terreno natural entre pozos, habrían circulado reatas de animales cargados con ladrillos, sillares y otros materiales, no pudiendo establecerse acopios a pie de obra, ni controlar la buena ejecución de los trabajos que habrían de quedar enterrados. Por el contrario, habría sido necesario habilitar depósitos de materiales en las zonas perimetrales al edificio, y efectuar penosos y continuos acarreos hasta los tajos de trabajo. Esta opción, por el contrario, no excluiría la posibilidad de que, en las futuras obras de la Universidad, se produjera la aparición de restos arqueológicos bajo rasante.

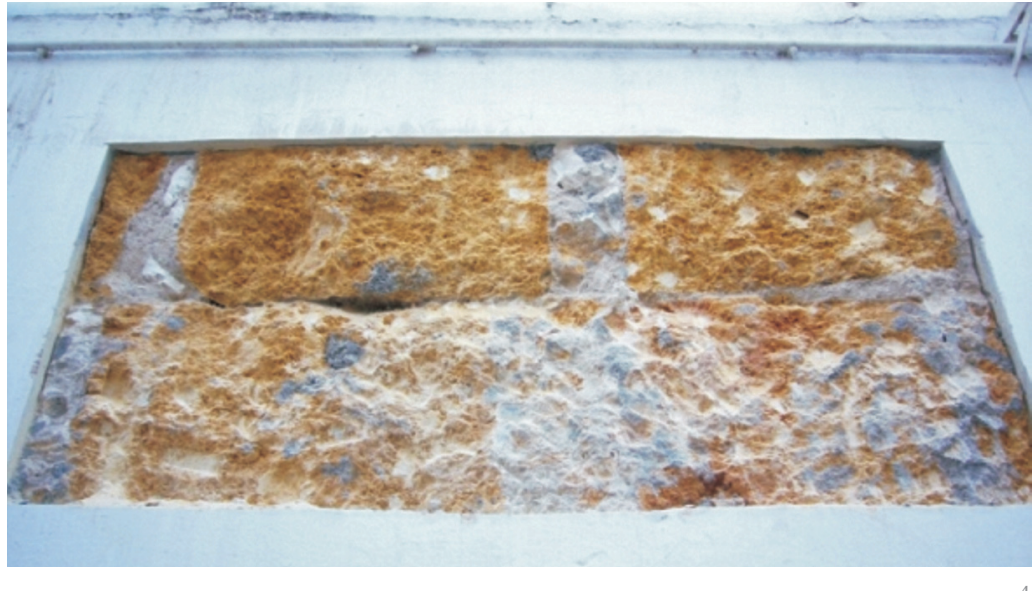

\section{PARTE EXPERIMENTAL}

Para obtener la debida información respecto a las tipologías de cimentaciones empleadas en el edificio de la Fábrica de Tabacos, se ha procedido a realizar tres catas, dos de ellas en zapatas visibles por estar ubicadas en zonas ocupadas por sótanos existentes en el edificio, y una tercera en una zapata no visible en la actualidad, al no haber sido afectado el sector en que se encuentra por la ejecución de sótanos. Se realiza también una cuarta cata en la cara superior del cimiento de un pilar primitivo eliminado en la intervención de la década de 1950, situado en el interior de un aula de la antigua Facultad de Derecho, hoy desocupada. Además se han extraído tres testigos cilíndricos de esta zapata. Pasamos a describir estos trabajos:

a) En el primero de los casos, analizamos un punto de la cimentación del cerramiento perimetral del edificio. Se trata de un sector de fachada en el que existe una escalera exterior de acceso a un pequeño sótano (Figura 3), lo que permite explorar la cimentación del muro en cuestión, que queda vista lateralmente. En este punto, observamos que el cimiento consiste en una zapata corrida realizada con sillería concertada de piedra arenisca sedimentaria (Figura 4).

b) También estudiamos un punto de la cimentación de uno de los numerosos pilares que quedan al descubierto en los sótanos ejecutado en la intervención de la década de los 50, para adaptar el edificio a sede de la Universidad. Tras la prospección, podemos comprobar la existencia de dos fábricas de distinto tipo de ladrillo, una que forma el perímetro exterior y que se adosa a la zapata original, y otra que compone el cimiento antiguo (Figura 5). La cara más externa corresponde a la intervención de la década de 1950, que ejecutó un muro de carga de ladrillo por delante de la zapata existente previamente excavada, para apoyar en él el forjado de techo del nuevo 
5. Cata realizada en cimiento de ladrillo situado en sótano de la Fábrica de Tabacos.

6. Arranque de pilar (demolido en la década 1950) sobre zapata de ladrillo macizo.

Zapata de ladrillo macizo bajo pilar de sillares de piedra en la Fábrica de Tabacos. sótano. Tras este muro, se observa la cara de otra fábrica de ladrillo correspondiente a la primitiva zapata, que aparece correctamente aparejada y enrasada en el plano vertical descubierto.

c) Exploramos también la cimentación de un pilar tipo no correspondiente a un sótano, para lo cual realizamos una excavación junto a una zapata de la zona de la secre-
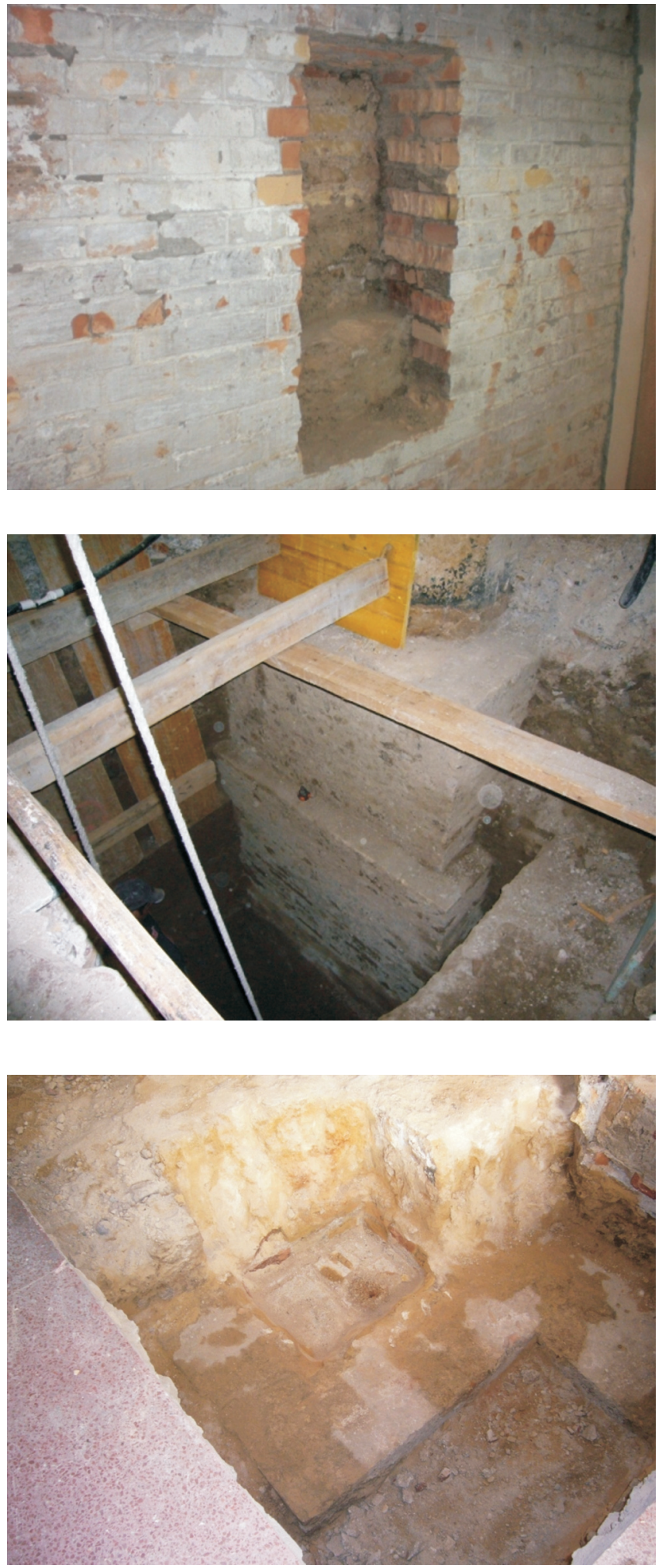

taría de la antigua Facultad de Derecho, hoy desocupada. En el pozo excavado para descubrir el lateral del cimiento, se observa que la zapata está construida con ladrillo macizo aparejado en todo su frente (Figura 6), habiéndose excavado hasta la base del cimiento situada a $-4,15 \mathrm{~m}$.

Es de señalar que, en el arranque de la zapata, existe una ampliación en planta de la misma con sus paramentos exteriores inclinados, generada a su vez por un gradiente de avance de cada hilada de ladrillo, a modo de mastaba. Es nuestra opinión que, una vez ejecutada la excavación general de la parcela y replanteadas las zapatas, debió parecer a los maestros de obras del edificio que el plano de asiento no tenía la capacidad de carga esperada, por lo que se decidió profundizar 1,10 m más en cada futura zapata, e iniciar su construcción en tronco de pirámide, lo que significaba contar con una planta sensiblemente mayor y apoyada en un estrato más resistente.

d) Se realiza una cata en la cara superior del cimiento de un pilar primitivo eliminado en la intervención de la década de 1950, situado en el interior de un aula de la antigua Facultad de Derecho, hoy desocupada (Figura 7), y se comprueba cómo el cimiento está ejecutado en todo su espesor con ladrillo macizo similar al aparecido en la cata del sótano, así como en la cata del lateral del cimiento de la secretaría de la antigua Facultad Derecho. Asimismo se extraen de esta zapata tres testigos con máquina perforadora, en una profundidad de 1,20 $\mathrm{m}$, resultando en todos ellos una fábrica homogénea de ladrillo y mortero de cal, regularmente aparejada (Figura 8).

Para la realización de las catas se han utilizado medios manuales, habiéndose procedido al levantado de las solerías de mármol y soleras de hormigón ejecutadas en la intervención de la década de los 50 del pasado siglo, y después a la excavación y consiguiente entibación de los pozos realizados, no habiendo aparecido ningún resto arqueológico en las zonas en cuestión. Los testigos cilíndricos se han obtenido utilizando una máquina cortadora de extracción de testigos de hormigón, refrigerada por agua.

Acompañamos un dibujo explicativo sobre la formación y tipología constructiva de los elementos de cimentación analizados (Figura 9).

\section{CONCLUSIONES}

De lo expuesto en el presente trabajo se deducen las siguientes conclusiones: 
a) El terreno donde se levantó el edificio era un territorio deprimido e inundable, situado entre los cauces del Guadalquivir y el Tagarete, de topografía sensiblemente horizontal, y cuya rasante natural se encontraba sensiblemente más baja que la actual rasante de la calle San Fernando.

b) Se convino desde un principio que la rasante de la planta baja del futuro edificio estuviera por encima de las avenidas del río, y se decidió excavar una media de 1,30 m en todo el solar, profundizándose además bajo cada zapata 1,10 m, hasta encontrar un firme adecuado.

c) Todo ello permitió la ejecución al aire de la totalidad de los cimientos, aún cuando su altura superaba los 4,00 m, por lo que se pudieron labrar las zapatas de abajo a arriba, como grandes pilares vistos, y rellenar después con tierra la parcela hasta la rasante acordada, a salvo de riadas.

d) Existen al menos dos tipos de cimentaciones: las de los muros de cerramientos exteriores e interiores, ejecutadas en sillería concertada, y las de los pilares, ejecutadas en fábrica de ladrillo macizo.

e) La dimensión en planta de los cimientos de ladrillo bajo los pilares va en aumento de arriba a abajo. Así, hasta 1,55 m de profundidad, la dimensión en planta del cimiento es de 2,00 ×2,00 m, aumentando hasta los 2,30 × 2,30 m entre esa cota y los 3,05 m. de profundidad. A partir de ahí y hasta la profundidad de 4,15 m que estimamos como fondo de cimentación, la fábrica de ladrillo conforma una figura de tronco de pirámide con una base final de $2,70 \times 2,70 \mathrm{~m}$.

f) Todo lo anteriormente descrito implicó la total desaparición de restos arqueológicos, de haber existido, hasta la cota de $-4,15 \mathrm{~m}$ desde la actual rasante de planta baja del edificio. Ello permitiría ahora a la Universidad de Sevilla ejecutar bajo la
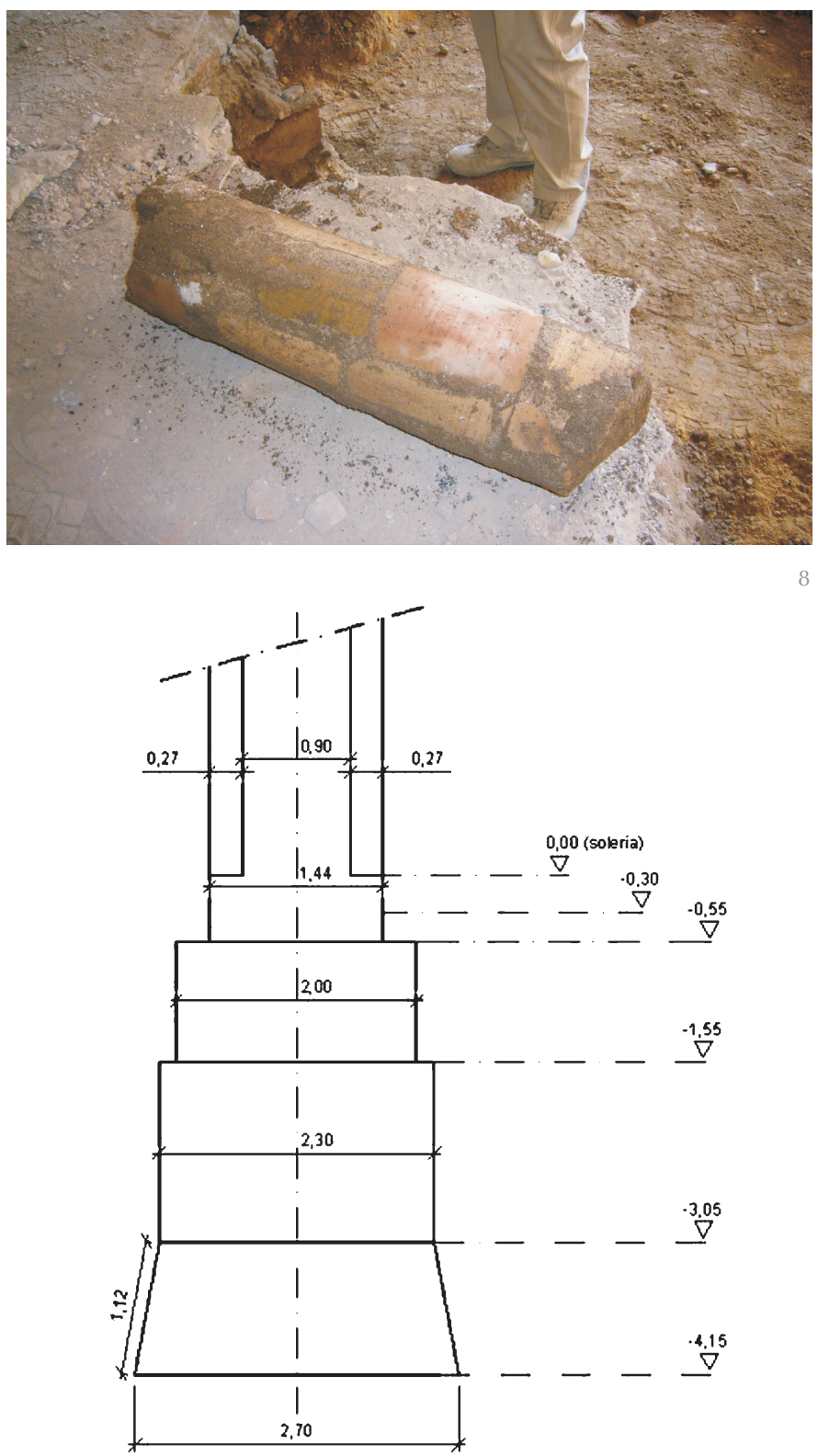

ESQUEMA COTAS PILAR EXENTO Y ZAPATA (Acolado en metros)

rasante del mismo las pretendidas galerías de instalaciones, con la seguridad de no encontrar restos arqueológicos anteriores a la construcción del edificio de la Fábrica de Tabacos.

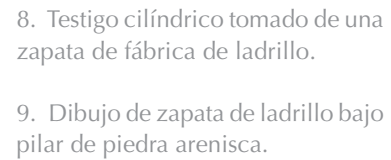

8. Testigo cilíndrico tomado de una 9. Dibujo de zapata de ladrillo bajo pilar de piedra arenisca.

\section{BIBLIOGRAFÍA}

1) J. M. Rodríguez et al.: Sevilla y el Tabaco, pp. 301, Sevilla, 1984

2) J. L. Trillo; M. González, et al. Universidad y Ciudad, pp. 36, Sevilla, 2002.

3) M. González Vílchez.: Plan Director de Remodelación de la Fábrica de Tabacos de la Universidad de Sevilla, pp. 15, Sevilla, 2009.

4) J. Morales: La Real Fábrica de Tabacos. Arquitectura, territorio y ciudad en la Sevilla del siglo XVIII, pp. 230, Sevilla, 1991. 